\title{
As novas reformas governativas em tempo de COVID-19 em Angola no atual contexto político e social e o enfrentamento das desigualdades sociais
}

\author{
Daniel Luciano Muondo ${ }^{1}$ \\ https://orcid.org/0000-0002-9224-0073
}

\author{
Cirlene Aparecida Hilário da Silva Oliveira ${ }^{2}$ \\ https://orcid.org/0000-0003-0045-5956
}

\footnotetext{
${ }^{1}$ Universidade Estadual Paulista, Faculdade de Ciências Humanas e Sociais, Programa de Pós-Graduação em Serviço Social, Franca, SP, Brasil

${ }^{2}$ Universidade Estadual Paulista, Faculdade de Ciências Humanas e Sociais Programa de Pós-graduação em Serviço Social, Franca, SP, Brasil
}

\begin{abstract}
As novas reformas governativas em tempo de COVID-19 em Angola no atual contexto político e social e o enfrentamento das desigualdades sociais

Resumo: O presente artigo faz uma abordagem sobre as reformas governativas em Angola em tempo de COVID-19 e as desigualdades sociais. O estudo é apresentado no quadro de apoio da CAPES, na condição de bolsista da UNESP-Franca e aponta as mudanças adotadas pelo governo angolano, com vista à contenção da pandemia e o reajuste da máquina administrativa, com a redução dos departamentos ministeriais e outras estruturas do poder executivo, extinguindo alguns e fundindo outros num único ente governativo. A situação da pandemia da COVID-19 está promovendo massivamente um contexto de desigualdades sociais, conduzindo as pessoas a viver em condições de precariedade e extrema pobreza, com níveis muito elevados de custo de vida. Todos nós e cada um em particular, estamos chamados a promover um ambiente de solidariedade, que contribua para a mitigação e/ou a resolução das desigualdades sociais, a redução dos índices de carência de bens e serviços nas comunidades. Este estudo apresenta o contexto atual do exercício do poder em Angola, com transformações na administração do Estado e as medidas de controlo da pandemia de COVID-19.
\end{abstract}

Palavras-chave: Angola. Governação. Desigualdades Sociais. COVID-19.

The new government reforms in time of COVID-19 in Angola in the current political and social context and the confrontation of social inequalities

Abstract: This article deals with government reforms in Angola in the time of COVID-19 and social inequalities. The study is presented in the CAPES support framework, as a scholarship holder from UNESP-Franca and points out the changes adopted by the Angolan government, with a view to containing the pandemic and the readjustment of the administrative machine, with the reduction of ministerial departments and other structures executive power, extinguishing some and merging others into a single governmental entity. The COVID-19 pandemic situation is massively promoting a context of social inequalities, leading people to live in precarious and extreme poverty conditions, with very high levels of living costs. All of us and each one in particular, are called to promote an environment of solidarity, which contributes to the mitigation and / or the resolution of social inequalities, the reduction of the need for goods and services in the communities. This study presents the current context of the exercise of power in Angola, with changes in the State administration and measures to control the pandemic of COVID-19.

Keywords: Angola. Governance. Social differences. COVID-19.

Recebido em 29.06.2020. Aprovado em 06.08.2020. Revisado em 07.10.2020.

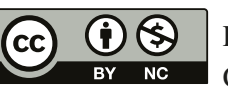

Este é um artigo publicado em acesso aberto (Open Access) sob a licença Creative Commons Attribution NonCommercial, que permite uso, distribuição e reprodução em qualquer meio, sem restrições desde que sem fins comerciais e que o trabalho original seja corretamente citado. 


\title{
Introdução
}

Angola é um país situado na África subsaariana, com uma população estimada em mais trinta milhões de habitantes. A governação iniciada em 2017, saída das quartas eleições gerais realizadas em setembro do mesmo ano, têm vindo a promover uma série de reformas administrativas ao nível das diferentes estruturas de poder, visando a melhoria das condições socioeconómicas dos cidadãos e a garantia da qualidade de vida, de modo geral.

O registro e a identificação de casos da pandemia de COVID-1 em Angola deram-se, inicialmente, desde o mês de março de 2020, importados a partir de Portugal, com a chegada de voos provenientes de Lisboa e do Porto, para o Aeroporto Internacional 4 de Fevereiro em Luanda, capital do país. A situação, ainda fora de domínio das autoridades angolanas naquela altura, obrigou a busca de experiências ao nível de outros países, a fim de lidar com o fenómeno.

Com ajuda de outros países, Angola, soberanamente, implementou medidas adequadas e profundas para a prevenção, o controlo e tratamento da pandemia de COVID-19, criando as condições desejadas para garantir a contenção da propagação da doença em todo território nacional, implementando reformas no aparelho governativo, com vista à diminuição das desigualdades sociais.

Por todo o país assistiu-se ao aumento dos atos de solidariedade para com as pessoas mais carenciadas, com a distribuição de bens alimentares, produtos de higiene e limpeza, criação de espaços de acolhimento para crianças, jovens e adultos sem abrigo e outras formas de ajuda possíveis.

\section{Angola e o Estado democrático de direito}

Angola é uma República soberana e independente, baseada na dignidade da pessoa humana e na vontade do povo angolano, que tem como objetivo fundamental a construção de uma sociedade livre, justa, democrática, solidária, de paz, igualdade e progresso social (ARAÚJO; NUNES; LOPES, 2014).

$\mathrm{O}$ artigo $1^{\circ}$ define o alcance e o objeto da Constituição que é Angola, enquanto comunidade política historicamente situada, independente, e que se fundamente na defesa da dignidade humana e na vontade do povo angolano. Este artigo traça os fundamentos da República de Angola, que se sintetizam na soberania, na dignidade da pessoa humana, na democracia, liberdade, justiça e paz, na solidariedade e igualdade social (ARAÚJO; NUNES; LOPES, 2014).

\begin{abstract}
A República de Angola é um Estado de Democrático de Direito, que tem como fundamentos a soberania popular, o primado da Constituição e da lei, a separação de poderes e interdependência de funções, a unidade nacional, o pluralismo de expressão e de organização política e a democracia representativa e participativa. A República de Angola promove e defende os direitos e liberdades fundamentais do homem, que como indivíduo, quer como membro de grupos sociais organizados, e assegura o respeito e a garantia da sua efetivação pelos poderes legislativo, executivo e judicial, seus órgãos e instituições, bem como por todas as pessoas singulares e coletivas. (ARAÚJO; NUNES; LOPES, 2014).
\end{abstract}

O Estado Democrático de Direito assenta em dois princípios fundamentais: o estado de direito e o princípio democrático. O primeiro apresenta como elementos caracterizadores: o princípio da constitucionalidade dos atos do Estado (princípio da Constituição), a divisão de poderes, entendido como princípio que exige a vinculação dos atos estaduais a uma competência, constitucionalmente definida e uma ordenação relativamente separada de funções (separação de poderes e interdependência de funções); o princípio de legalidade da administração, que se consubstancia nos princípios da supremacia ou prevalência da lei, uma vez que para um Estado de Direito a lei é a expressão privilegiada do princípio democrático e o instrumento mais apropriado e seguro para definir os regimes de certas matérias, sobretudo dos direitos fundamentais (princípio da lei); e, a independência dos tribunais, institucional e funcional e vinculação do juiz à lei.

O princípio do Estado de Direito pressupõe, igualmente, a garantia da proteção jurídica e abertura da via judiciária, para se assegurar ao cidadão uma defesa sem lacunas, bem como o princípio da proporcionalidade ou princípio da proibição dos excessos que assegura os limites do Estado em caso da declaração de estado do 
sítio ou de exceção e na limitação das restrições de direitos, liberdades e garantias dos cidadãos e, finalmente, funciona como um princípio básico das medidas de polícia.

Por sua vez, o princípio democrático apresenta como princípios formais caracterizadores o princípio da soberania popular para quem a legitimação do domínio político só pode derivar do povo e nunca de qualquer outra entidade; o princípio da representação, que assenta em postulados que estabelecem que o exercício jurídico de funções de domínio, constitucionalmente autorizado é feito em nome do povo, por órgão de soberania do Estado, que há uma derivação direta da legitimação de domínio do princípio de soberania popular e que o exercício do poder tem em vista prosseguir os fins ou interesses do povo e, ainda, o princípio do sufrágio que está ligado ao princípio anteriormente enunciado - o princípio da representação. Ele manifesta-se no direito de voto para escolha dos seus representantes.

O Estado Democrático de Direito é um estado constitucional, que define o primado da Constituição sobre todos os atos políticos, administrativos, jurisdicionais do Estado.

\section{O conceito de Estado}

O Estado que entendemos como o conjunto de instituições que controlam e administram uma nação - grupo étnico politicamente consciente, grupo de pessoas com determinadas tendências comuns de ordem moral, cultural e psicológica - é possível que tenha surgido como o instrumento por meio do qual os homens exercitam a força da cooperação entre eles e, assim, conseguiriam enfrentar com melhores resultados as adversidades do meio ambiente.

Desde há muito que a Teoria do Estado procuras defini-lo com base na doutrina de três elementos. De acordo com o entendimento, um Estado compreende em princípio um povo, um território e um governo soberano. Esta doutrina vale de forma meramente tendencial. Assim, por exemplo, se se pensar no conceito de povo com base nos critérios tradicionais da etnia, da cultura e da língua, hoje largamente superados, verifica-se que um povo pode existir em diferentes Estados, assim como um Estado pode conter vários povos. Em todo o caso, o Estado pode caracterizar-se, juridicamente, como o detentor, dentro de um território, do poder soberano, quer em face dos sujeitos externos a este território, a soberania externa, quer em face dos sujeitos que residam, ou atuem no seu interior, a soberania interna. (MACHADO; COSTA; HILÁRIO, 2013, p. 14).

Como enunciou Thomas Hobbes ${ }^{1}$ (1588-1679), o Estado surge para evitar a desagregação que sempre ameaçou os homens (HOBBES, 2002 apud QUEIROZ, 2012). De forma simplificada, podemos perceber o Estado como um contrato social (representado por uma Constituição) que os homens fazem entre si e no qual cada um cede uma parte de sua liberdade, para que este possa regular as relações entre eles e, assim, prover a prosperidade de todos.

O Estado pode ser definido tanto em termos das instituições que o formam quanto das funções que estas instituições desempenham. Instituições do Estado compreendem órgãos legislativos, incluindo assembleias parlamentares e instituições subordinadas voltadas à elaboração de leis; órgãos executivos, incluindo departamentos governamentais e ministérios; e órgãos jurídicos - principalmente tribunais - com a responsabilidade de obrigar ao cumprimento da lei e de aperfeiçoá-la por intermédio de suas decisões. Há diferenças entre sistemas políticos no que diz respeito ao grau em que instituições legislativas, executivas e judiciárias encontram-se claramente separadas umas das outras ou sobrepõem-se. (HAM; HILL, 1993, p. 40).

As instituições do Estado são representativas do poder executivo, enquanto governo, legitimadas para o exercício de funções políticas e administrativas, que concorrem para a organização da vida pública em todas as suas formas, considerando a satisfação dos interesses dos cidadãos, como legítimos detentores da soberania popular.

A intervenção do governo ocorre pelas políticas públicas. Apenas o governo pode implementá-las porque possui a capacidade de universalização, coerção e regulamentação e pode adotar medidas com carácter universal, que atenda a todo povo ou de forma generalizada tenha maior poder de alcance. O governo também 
pode estabelecer penalidades para quem não cumpre aquelas demandas e pode estabelecer regras que devem ser cumpridas pela sociedade. Essa capacidade é estabelecida pela governabilidade.

De acordo com o economista e cientista social Luiz Carlos Bresser Pereira (1995 apud QUEIROZ, 2012, p. 8), "o Estado é uma organização burocrática ou aparelho que se diferencia essencialmente das demais organizações porque é a única que dispõe de poder extroverso - de um poder político que ultrapassa os seus próprios limites organizacionais".

Assim, em determinado momento da história, o Estado foi obrigado a alterar seu modelo e/ou suas funções para se adequar às novas exigências que passam a ser requeridas pelas mudanças no ambiente tecnológico, económico e social. é o que vem ocorrendo na maioria dos países desde a década de 1970.

O Estado moderno, que teve início no século XVI, trouxe a organização em torno da racionalidade, do Estado de direito, que são as leis nacionais negociadas num grande acordo social, a Constituição. O Estado é uma estrutura que se destaca da sociedade: os cidadãos dão o voto para a formação de uma superestrutura política; o Estado moderno é uma grande máquina política que se estrutura com base na sociedade, com o objetivo de gerenciá-la dentro de uma estrutura legal.

Um Estado existe quando há um aparelho político de governo (instituições como um parlamento ou congresso, mais funcionários públicos), que governam um dado território, cuja autoridade é apoiada por um sistema legal e pela capacidade de usar a força militar para implementar as suas políticas. O poder é a capacidade que indivíduos ou grupos possuem para fazer valer os seus próprios interesses, mesmo quando outros se opõem. Por vezes, isso requer o uso direto da força. O poder é um elemento que se encontra em todas as relações sociais, tal como entre a entidade patronal e os trabalhadores. A autoridade é o uso legítimo do poder pelo governo. A legitimidade significa que aqueles que se submetem à autoridade do governo consentem nela. (GIDDENS, 2008, p. 424-425).

A implementação do poder por parte do Estado requer o exercício da autoridade que lhe é conferida pela Constituição e por outros instrumentos legais, como garantia legítima, soberana e de domínio público. Não se trata de uma autoridade exercida à margem da lei, mas que assenta em princípios e normas legalmente aceitos, pois, mesmo o uso da força militar deve ser exercido nos termos previamente definidos no quadro da legalidade.

\section{As reformas governativas do aparelho do Estado em Angola no contexto da COVID-19 e o exercício do poder político}

O surgimento da pandemia da COVID-19 em Angola ocasiona a implementação de reformas no aparelho governativo, como medida de ajustamento das políticas públicas, mas, sobretudo, como forma de contenção de gastos para a estabilidade económica e social do país, por um lado por outro, no sentido de conter a propagação da doença da COVID-19, implementou uma série de medidas sanitárias, para a prevenção e o controlo da pandemia. Deste modo, o poder executivo viu-se obrigado, também, a reformular o governo, diminuindo os departamentos ministeriais, bem como os cargos de direção e chefia no aparelho do Estado.

O Decreto Legislativo Presidencial N. ${ }^{\circ}$ 5/20, de 15 de Abril aprova a alteração à organização e funcionamento dos órgãos Auxiliares do Presidente da República, constituindo 21 (vinte e um) Departamentos Ministeriais e 1 (um) Secretariado do Conselho de Ministros, que resultou da fusão e extinção de estruturas governativas e correspondentes funções da então vigente máquina administrativa pública (ANGOLA, 2020).

Assim, nos termos do $36^{\circ}$ Artigo do referido Decreto, passaram a existir os seguintes Departamentos Ministeriais (ANGOLA, 2020):

a) Ministério da Defesa Nacional e Veteranos da Pátria;

b) Ministério do Interior;

c) Ministério das Relações Exteriores;

d) Ministério das Finanças;

e) Ministério da Economia e Planeamento;

f) Ministério da Administração do Território;

g) Ministério da Justiça e dos Direitos Humanos; 
h) Ministério da Administração Pública, Trabalho e Segurança Social;

i) Ministério da Agricultura e Pescas;

j) Ministério da Indústria e Comércio;

k) Ministério dos Recursos Minerais, Petróleo e Gás;

1) Ministério das Obras Pública e Ordenamento do Território;

m) Ministério da Energia e Águas;

n) Ministério dos Transportes;

o) Ministério das Telecomunicações, Tecnologias de Informação e Comunicação Social;

p) Ministério do Ensino Superior, Ciência, Tecnologias e Inovação;

q) Ministério da Saúde;

r) Ministério da Educação;

s) Ministério da Cultura, Turismo e Ambiente;

t) Ministério da Acção Social, Família e Promoção da Mulher;

u) Ministério da Juventude e Desportos.

De acordo ainda com o Artigo citado do mesmo Decreto, acrescenta-se aos Departamentos Ministeriais um Secretariado do Conselho de Ministros. (ANGOLA, 2020).

Outra medida adotada pelo governo de Angola foi a redução dos cargos de direção e chefia, de 559 para 313, ao nível dos departamentos ministeriais e instituições públicas, o que permitirá que o Estado poupe cerca de 96,5 milhões de kwanzas por mês, correspondente a mais de mil milhões de kwanzas anuais. No quadro de uma visão integrada das ações de reforma do Estado, o processo começou com o Decreto Presidencial 5/20, que alterou a estrutura orgânica do Governo, passando de 28 para 21 Ministérios. (JORNAL DE ANGOLA, 2020).

A nova orgânica visou modernizar e racionalizar a Administração Central e melhorar o grau de eficiência e eficácia na prestação de serviço ao cidadão, cuja estratégia global consiste na continuidade da racionalização, o máximo possível, com a redução das estruturas administrativas, de modo a conseguir, por via disso, algum ganho financeiro.

Com essa medida, foram apreciados os Estatutos Orgânicos dos Ministérios da Indústria e Comércio; da Administração do Território; da Defesa Nacional e Veteranos da Pátria; da Cultura, Turismo e Ambiente; das Obras Públicas e Ordenamento do Território; dos Recursos Minerais, Petróleo e Gás; das Telecomunicações, Tecnologias de Informação e Comunicação Social; e, da Agricultura e Pescas.

Com a medida adotada, os recursos financeiros postos, até então, ao serviço da máquina administrativa sejam postos, doravante, ao serviço do sector social, com o reforço do investimento nos domínios da Educação, Saúde e em outros domínios de interesse público. Tratou-se de um primeiro exercício, com carácter contínuo, a nível dos institutos públicos, enquadrando, assim, na estratégia global de reforma de Estado que é adequar a máquina administrativa do Estado à capacidade financeira.

O processo, como um todo, assenta em três pilares: orçamental, infraestrutural e do pessoal. Na componente orçamental, a fusão dos Ministérios redunda em poupanças substanciais, tal como deve ocorrer com a dimensão infraestrutural, unindo os Ministérios antes dispersos em edifícios diferentes, a funcionar num único, obtendo-se também algum ganho. No plano do pessoal, a questão fica como objeto de tratamento específico.

Na nova composição ficaram intactos os Ministérios das Relações Exteriores, da Economia e Planeamento, das Finanças, da Administração do Território, da Administração Pública, Trabalho e Segurança Social, da Justiça e dos Direitos Humanos, da Energia e Águas, da Educação, da Saúde, do Ensino Superior, Ciência e Inovação; da Ação Social, Família e Promoção da Mulher, e o da Juventude e Desportos.

A fusão dos departamentos ministeriais permitiu ao governo reduzir a sua máquina administrativa, diminuindo os custos com os detentores de cargos públicos, canalizando mais recursos financeiros para os cofres do Estado e, por sua vez, contribuam no aumento da oferta de bens e serviços aos cidadãos.

As reformas no aparelho governativo do Estado em Angola em tempo de pandemia constituíram medidas do executivo para o controlo da economia, considerando as limitações na importação de bens de consumo, $\mathrm{o}$ incentivo às iniciativas microeconómicas ao empresariado nacional e, consequentemente, a aposta na produtividade local. 


\section{As medidas governativas na prevenção e combate à pandemia da COVID-19 em Angola}

O mundo continua assolado por uma pandemia de alto contágio, causada pela COVID-19, que coloca em causa a estabilidade das relações sociais e a sustentabilidade do tecido socioeconómico. As ações implementadas pelo Executivo angolano foram prontas e de intensidade variável e adaptável tendo culminado com a Declaração do Estado de Emergência, por três vezes prorrogada e, em determinado momento, com a promulgação da situação de Calamidade, através do Decreto Presidencial n. ${ }^{\circ}$ 142/20, de 25 de maio, declarada a Situação de Calamidade Pública a partir da meia-noite (0h00) do dia 26 de maio de 2020, que se prolonga enquanto se mantiver o risco de propagação massiva do Vírus SARS-COV-2 e da Pandemia COVID-19 (ANGOLA, 2020b).

Apesar da subsistência do risco de contágio, urge, cada vez mais, a garantia de um melhor equilíbrio entre a estratégia sanitária de prevenção e combate e a necessidade de relançar gradualmente a atividade económica, formal e informal, em especial aquelas usadas como meio de subsistência, e o regresso à normalidade da vida social. Ou seja, sem descurar as regras de prevenção e combate à Pandemia COVID-19, é necessário criar condições para adaptação a uma nova postura social, capaz de garantir, com segurança, a gradual retoma da vida económica e social.

O controlo da propagação da COVID-19 em Angola teve início com a promulgação do Decreto Legislativo Presidencial Provisório n. ${ }^{\circ}$ 1/20, de 18 de março (ANGOLA, 2020a) considerando que foi declarada como pandemia pela Organização Mundial da Saúde a infeção causada pelo vírus COVID-19, por se assistir a uma alta taxa de mortalidade e pelo seu impacto social e económico negativo em todo o mundo, tornando-se necessário tomar medidas urgentes em defesa do interesse público, com vista a se reforçarem as providências já tomadas para se evitar a importação de casos e salvaguardar a vida e a saúde da população em geral.

Este Decreto definiu, nos artigos $1^{\circ}$ ao $4^{\circ}$ a interdição da circulação fronteiriça, a proibição dos aglomerados sociais, a observação do período de quarentena pelos passageiros e, a implementação pelos órgãos da administração do Estado (ANGOLA, 2020a).

A circulação fronteiriça suspendeu todos os voos comerciais e privados de passageiros, de Angola para o exterior e vice-versa por 15 (Quinze) dias, prorrogáveis por igual período de tempo, em função do comportamento global da pandemia do COVID-19, a partir das 0:00 (zero) horas do dia 20 de março de 2020, não abrangendo os voos de carga, nem aqueles que sejam indispensáveis por razões humanitárias ou que estejam a serviço da execução da política externa de Angola (ANGOLA, 2020a).

A interdição da circulação de pessoas nas fronteiras terrestres observou-se a partir das 0:00 (zero) horas do dia 20 de março de 2020, por 15 (quinze) dias, prorrogáveis por igual período de tempo, em função do comportamento global da pandemia do COVID-19. Ficou interdita a atracagem e o desembarque de navios de passageiros e respetivas tripulações, provenientes do exterior do País, em todos os portos nacionais a partir das 0:00 (zero) horas do dia 20 de março de 2020, por 15 (quinze) dias, prorrogáveis por igual período de tempo, em função do comportamento global da pandemia do COVID-19, cuja não se aplica à atracagem e ao desembarque de navios de carga. Apenas ficou permitido o desembarque das tripulações dos navios de carga em caso de necessidade de assistência por razões médicas e humanitárias, observando-se em todo o caso o protocolo de prevenção estabelecido para o combate à pandemia do COVID-19 (ANGOLA, 2020a).

A realização de eventos públicos como cultos religiosos, atividades culturais, recreativas, desportivas, políticas, associativas, turísticas, privadas e de qualquer outra índole, com a aglomeração de mais de 200 (duzentas) pessoas ficou proibida. Todos os estabelecimentos públicos e privados, incluindo centros comerciais, mercados, restaurantes, bares, lanchonetes, estações ferroviárias e rodoviárias, portos, aeroportos, locais de culto, escritórios, escolas e outros locais de congregação que se mantivessem abertos ao público deviam criar as condições adequadas e acessíveis para a higiene das mãos, com sabão e água corrente, ou desinfetante à base de álcool, tendo-se recomendada a todos cidadãos a observância de restrição no contacto pessoal próximo, como apertos de mão e abraços, principalmente em ambientes congregacionais, como escolas, escritórios, locais de culto e outros (ANGOLA, 2020a).

É recomendada a todos os cidadãos a observância permanente de medidas de higiene que evitem o contágio, a participação em reuniões não necessárias, bem como a realização de viagens ao interior e exterior do País que não sejam essenciais. É especialmente recomendada a observância de rigorosas normas de higiene, nos termos das recomendações do Ministério da Saúde, nos meios de transporte coletivo de passageiros, como autocarros, táxis, comboios, aviões e navios (ANGOLA, 2020a). 
O Decreto estabeleceu que todos os passageiros que desembarcassem nos aeroportos nacionais até as 0:00 (zero) horas do dia 20 de março de 2020 devem preencher no momento do desembarque o formulário para o controlo sanitário obrigatório, entregue pelas autoridades competentes, e ficar em casa por um período mínimo de 14 (catorze) dias, cumprindo as orientações dadas para o efeito pelo Ministério da Saúde, com a proibição das visitas aos cidadãos abrangidos, durante o período de tempo em que estivessem em quarentena (ANGOLA, 2020a).

As administrações e direções das instituições da Administração Central e Local do Estado, bem como as entidades patronais das empresas públicas e privadas, deviam considerar como justificada a ausência ao trabalho dos cidadãos, que resultassem da observância do período de quarentena, nos termos do disposto no Decreto Presidencial.

Os órgãos competentes do Estado afetos aos Ministérios da Saúde, do Interior, da Defesa Nacional e dos Transportes deviam, de modo articulado, zelar pelo cumprimento e materialização do disposto no Diploma, podendo recorrer a colaboração especializada das entidades públicas e privadas que julgassem necessárias, em função da natureza das tarefas a executar para a implementação das orientações emanadas, sendo delegadas competências regulamentares a cada um dos Titulares dos Departamentos Ministeriais em função da matéria, relativamente à necessidade de se tomarem eventuais medidas adicionais que reforçassem o controlo sanitário, migratório e de ordem pública, exigidos no âmbito da prevenção e contenção da expansão da pandemia COVID-19.

\section{O enfrentamento das desigualdades sociais em época de COVID-19}

As questões de desigualdades e a justiça social estão relacionadas com a exclusão social, o que permite, também, lidar com a forma como a sociedade está estruturada e organizada, e com as lógias que são um obstáculo ao combate à pobreza e, portanto, também, um obstáculo à construção de uma sociedade justa, igualitária e democrática.

Pobreza e exclusão social não são dados naturais, são antes produto de relações sociais desiguais face à luta travada pelos indivíduos, numa dada sociedade, pelo acesso aos recursos de sobrevivência. Porque produto de relações sociais e construção social, a exclusão social, historicamente, esteve ligada aos sistemas de classificação sobre o normal e o patológico. Os sistemas de classificação, entre muitas finalidades, constituem, na verdade, mecanismos tradicionais de controlo social em relação aos indivíduos ou grupos de indivíduos que podem comprometer a segurança ou ordem pública (criminosos, delinquentes, etc.), ou daqueles que podem pôr em perigo a sociedade genericamente considerada (indivíduos com doenças crónicas e/ou contagiosas). (ARRUDA; COLAÇO; BAIA, 2014, p. 33).

As desigualdades sociais não são produto do acaso, ou de uma condição natural, mas sim, situações criadas pelas próprias instituições ou governos, resultantes da falta de organização estrutural e funcional no contexto da governação central e local do Estado, o que pode dar origem ao surgimento de vários fenómenos sociais, que podem comprometer a vida dos cidadãos em particular e das estruturas governativas, de modo geral.

A prevalência da situação de COVID-19 agudizou a questão das desigualdades sociais, com a existência de muitas pessoas sem o mínimo de condições de sobrevivência, faltando-lhes até, as mais básicas necessidades, como a alimentação, higiene e saneamento e meios de biossegurança. Esta problemática viu-se minimizada com o eclodir de atos de solidariedade, promovidas por organizações da sociedade civil, indivíduos particulares e complementadas por estruturas governamentais, apoiando com bens de necessidades básicas.

As desigualdades sociais constituem a característica estrutural das sociedades humanas, derivando das diferenças no acesso aos recursos variados entre os indivíduos, o que, por sua vez, afeta significativamente a qualidade de suas vidas. A estratificação social remete para um sistema de desigualdades estruturadas entre os diferentes agrupamentos de pessoas. A estratificação social expressa-se na disposição da sociedade em estratos hierarquizados com os mais favorecidos no topo e os menos privilegiados na base. (GIDDENS, 2000 apud ARRUDA; COLAÇO; BAIA, 2014, p. 61). 
As condições de vida das pessoas são agravadas, muitas vezes, pela falta de bens e serviços básicos, o que chega a comprometer o seu modo de vida, na relação com as demais que se encontram nos mesmos espaços territoriais ou em áreas habitacionais diferentes, muitas vezes, marcados pelas estruturas hierárquicas de poder e de dominação.

Ferreira (1995 apud ARRUDA; COLAÇO; BAIA, 2014, p. 61) define desigualdade social como:

uma diferença constituída socialmente no acesso aos recursos de diversa natureza. Deste modo, o facto de se possuir maior ou menor riqueza, prestígio social, nível de escolarização e sucesso escolar; capacidade de exercício de poder ou de cidadania, entre outros campos, depende dos mecanismos sociais adotados e que condicionam os destinos dos indivíduos.

Os cidadãos devem ter acesso aos recursos produzidos pelo país numa proporção equilibrada, beneficiando a todos, independentemente da sua condição social, pois que, devem merecer um tratamento igual da sua distribuição. A equidade social é um princípio de cidadania, que deve ser exercitado no combate contra as desigualdades sociais, promovendo um nível de vida dignificante para os indivíduos, na sua relação com o meio envolvente e, de acordo com as suas reais necessidades, como também, com aquelas sentidas no quotidiano das suas vidas.

As desigualdades sociais expressam-se através dos sistemas de estratificação social. A desigualdade está incrustada no tecido social de todas as sociedades através do sistema de estratificação social ou do posicionamento de grupos de indivíduos na sociedade, perpetuando os ganhos (recompensas) desiguais e as oportunidades sociais da vida. Assim sendo, os grupos sociais estão organizados por sobreposição do topo à base. Todas as sociedades passadas e recentes tiveram ou têm alguma forma de estratificação, embora o grau de desigualdade entre os estratos sociais possa variar. (NEWMAN, 1997 apud ARRUDA; COLAÇO; BAIA, 2014, p. 61).

A estrutura das sociedades reflete uma hierarquização de segmentos ou estratos sociais, produzidos segundo diversas características como: sexo, idade, categoria socioprofissional, etnia etc. ora, frequentemente, estas características são utilizadas isoladamente e/ou em simultâneo, para a produção de desigualdades sociais. Pois, as características fisiológicas, só por si, não produzem a desigualdade social, na medida em que fatores como a cor dos olhos, a estatura física, gostos artísticos etc., não influenciam as oportunidades de vida concreta ou as posições sociais dos indivíduos. A desigualdade social resulta, sim, de um acesso desigual aos bens, serviços ou oportunidades, cuja razão explicativa se encontra nos mecanismos que estruturam a própria sociedade.

\section{Considerações finais}

O exercício do poder político em Angola é legitimado pelo voto popular nas eleições gerais, que se realizam regularmente em todo o território nacional, num período de cinco anos. O Estado como ente governativo tem por objetivo trabalhar para o bem de todos os cidadãos, promovendo o direito a justiça, a paz a igualdade e a fraternidade.

Para garantir os direitos dos cidadãos, o Estado e as demais estruturas governativas que exercem o poder político ao nível central e local providenciam as condições necessárias aos cidadãos, com a garantia de bens e serviços propícios para uma vida com dignidade, sobretudo, no combate às desigualdades sociais, em qualquer contexto ou situação que o país se encontre.

Em tempo da pandemia de COVID-19, agudizaram-se as desigualdades sociais, com o aumento das necessidades de bens e serviços por parte dos cidadãos, observando-se, por um lado, a degradação do nível de vida das pessoas e, por outro, a sensibilização da sociedade civil para a promoção de ações de solidariedade, com o objetivo de apoiar diante da situação de carência.

Em qualquer contexto de vida que um país se possa encontrar, o Estado tem legitimidade para implementar mudanças ou transformações, diante da realidade socioeconómica, com vista a conter a propagação do fenómeno e a garantia da proteção dos direitos dos cidadãos, tanto ao nível da capacidade interna, quanto com recurso a apoios externos. 


\section{Referências}

ANGOLA. Decreto legislativo presidencial n. ${ }^{\circ}$ 5/20, de 15 de abril. Aprova a alteração à organização e funcionamento dos órgãos Auxiliares do Presidente da República. [Luanda]: Diário da República, 2020. Disponível em: https://angolaforex.com/2020/04/15/ diario-da-republica-i-a-serie-n-o-49-de-15-de-abril-de-2020/. Acesso em: 26 ago. 2020.

ANGOLA. Decreto legislativo presidencial provisório n. ${ }^{\circ}$ 1/20, de 18 de março. Aprova o acordo entre o Governo da República de Angola e o Governo da República Portuguesa sobre Promoção Recíproca de Investimentos. [Luanda]: Diário da República, 2020a. Disponível em: https://www.covid19.gov.ao/assets/arq_pdf/2020DRI031.pdf. Acesso em: 26 ago. 2020.

ANGOLA. Decreto presidencial n. ${ }^{\circ}$ 142/20, de 25 de maio. Declara a situação de Calamidade Pública a partir das 0h00 do dia 26 de maio de 2020, que se prolonga enquanto se mantiver o risco de propagação massiva do Vírus SARS-COV-2 e da Pandemia COVID-19. Revoga todos os actos praticados pelos Órgãos da Administração Central e Local que contrariem o disposto no presente Diploma. [Luanda]: Diário da República, 2020b. Disponível em: https://www.tralac.org/documents/resources/covid-19/countries/3679-angolastatement-on-covid-19-pandemic-25-may-2020/file.html. Acesso em: 26 ago. 2020.

ARAÚJO, R. C. V.; NUNES, E. R.; LOPES, M. Constituição da república de angola anotada. Porto: Luanda, 2014. T. 2.

ARRUDA, R.; COLAÇO, J.; BAIA, A. O que é Exclusão Social? Lisboa: Escolar Editora, 2014.

GIDDENS, A. Sociologia. Lisboa: Fundação Calouste Gulbenkian, 2008.

HAM, C. HILL, M. O Processo de Elaboração de Políticas no Estado Capitalista Moderno. Tradução de Renato Amorim e Renato Dagnino. Campinas: DPCT/UNICAMP, 1993.

JORNAL DE ANGOLA. Edição 15 de Maio de 2020.

MACHADO, J. E. M.; COSTA, P. N. da; HILÁRIO, E. C. Direito Constitucional Angolano. [S. 1.]: Coimbra, 2013.

QUEIROZ, R. B. Formação e gestão em políticas públicas. Curitiba: Intersaberes, 2012.

\section{Nota}

1 Matemático, teórico e político, filósofo inglês. Acreditava que os homens só viveriam em paz se concordassem em se submeter a um poder absoluto e centralizado (HOBBES, 2002 apud QUEIROZ, 2012).

\section{Daniel Luciano Muondo}

dmuondo@gmail.com

Doutorando do Programa de Pós-Graduação em Serviço Social da Universidade Estadual Paulista (UNESP) Mestre em Governação e Gestão Pública pela Universidade Agostinho Neto - Luanda-Angola.

Docente Assistente no Curso de Licenciatura em Serviço Social do Instituto Superior de Serviço Social de Luanda (ISSS).

Docente Convidado no Curso de Mestrado em Serviço Social e Política Social do Instituto Superior João Paulo II (ISUP JP II) da Universidade Católica de Angola (UCAN)

\section{ISSS}

Av. Fidel Castro Ruz - Via Expressa - Estrada Circular de Viana-Cabolombo, Bairro Bnenfica. Luanda-Angola.

\section{Cirlene Aparecida Hilário da Silva Oliveira}

cirleneoliveira@terra.com.br

Doutora em Serviço Social pela Universidade Estadual Paulista (UNESP)

Professora do Programa de Pós-graduação em Serviço Social da Universidade Estadual Paulista (UNESP) Professora Visitante do Programa de Pós-graduação em Políticas Públicas da Universidade Federal do Piauí (UFPI) 


\section{UNESP}

Av. Eufrásia Monteiro Petráglia, 900 - Jardim Antonio Petraglia

Franca - SP - Brasil

CEP: $14.409-160$

\section{Agradecimentos}

Nossos agradecimentos à CAPES, através da UNESP-Franca,

Faculdade de Ciências Humanas e Sociais, no apoio ao curso de Doutorado em andamento, pelo Programa de Pós-Graduação em Serviço Social.

À Revista Katálysis, pela aceitação e revisão do manuscrito, considerando a relevância do tema do artigo, para sua publicação.

Agência financiadora

Não se aplica.

Contribuições dos autores

Artigo resultante dos estudos realizados pelo Doutorando
Daniel Luciano Muondo, sob orientação da $\operatorname{Prof}^{\mathrm{a}} \operatorname{Dr}^{\mathrm{a}}$ Cirlene Aparecida Hilário da Silva Oliveira. Apresenta análise da atual conjuntura do exercício de poder em Angola, as transformações do Estado e as medidas de controle da pandemia da Covid-19. $\mathrm{O}$ artigo integra a pesquisa de Doutorado em Serviço Social e teve a contribuição dos dois autores.

Aprovação por Comitê de Ética

Não se aplica.

Consentimento para publicação

Consentimento dos autores.

Conflito de interesses

Não há conflito de interesses. 